\title{
Toxicity of antidepressants: rates of suicide relative to prescribing and non-fatal overdose
}

\author{
Keith Hawton, Helen Bergen, Sue Simkin, Jayne Cooper, Keith Waters, David Gunnell
} and Navneet Kapur

\section{Background}

Self-poisoning is a common method of suicide and often involves ingestion of antidepressants. Information on the relative toxicity of antidepressants is therefore extremely important.

\section{Aims}

To assess the relative toxicity of specific tricyclic antidepressants (TCAS), a serotonin and noradrenaline reuptake inhibitor (SNRI), a noradrenergic and specific serotonergic antidepressant (NaSSA), and selective serotonin reuptake inhibitors (SSRIS).

\section{Method}

Observational study of prescriptions (UK), poisoning deaths involving single antidepressants receiving coroners' verdicts of suicide or undetermined intent (England and Wales) and non-fatal self-poisoning episodes presenting to six general hospitals (in Oxford, Manchester and Derby) between 2000 and 2006. Calculation of fatal toxicity index based on ratio of rates of deaths to prescriptions, and case fatality based on ratio of rates of deaths to non-fatal self-poisonings.

\section{Results}

Fatal toxicity and case fatality indices provided very similar results (rho for relative ranking of indices 0.99 ). Case fatality rate ratios showed greater toxicity for TCAs $(13.8,95 \% \mathrm{Cl}$ 13.0-14.7) than the SNRI venlafaxine $(2.5,95 \% \mathrm{Cl} 2.0-3.1)$ and the NaSSA mirtazapine $(1.9,95 \% \mathrm{Cl} 1.1-2.9)$, both of which had greater toxicity than the SSRIS $(0.5,95 \% \mathrm{Cl} 0.4-0.7)$. Within the TCAs, compared with amitriptyline both dosulepin (relative toxicity index 2.7) and doxepin (2.6) were more toxic. Within the SSRIS, citalopram had a higher case fatality than the other SSRIS $(1.1,95 \% \mathrm{Cl} 0.8-1.4$ v. 0.3, 95\% Cl 0.2-0.4).

\section{Conclusions}

There are wide differences in toxicity not only between classes of antidepressants, but also within classes. The findings are relevant to prescribing decisions, especially in individuals at risk, and to regulatory policy.

\section{Declaration of interest}

D.G. is a member of the Medicines and Healthcare products Regulatory Agency's Pharmacovigilance Expert Advisory Group.
Self-poisoning is a common method of suicide, especially in women. ${ }^{1}$ Antidepressants are frequently used for self-poisoning, being involved in around $20 \%$ of all poisoning suicides in the $\mathrm{UK}^{1}$ and in $20-30 \%$ of non-fatal overdoses. ${ }^{2}$ This reflects the facts that depression is the most frequent psychiatric disorder in people dying by suicide, ${ }^{3}$ the method used for suicidal acts is often determined by availability, ${ }^{4}$ and self-poisoning in individuals with depression often involves antidepressants prescribed for them. ${ }^{5}$ Relative toxicity is an important factor likely to determine the outcome of an antidepressant overdose. Studies using different approaches have shown wide variation in the relative toxicity of antidepressants, ${ }^{6,7}$ with the older tricyclic antidepressants (TCAs) generally being more toxic than the newer selective serotonin reuptake inhibitors (SSRIs). ${ }^{6,7}$ We have used two approaches to assessing the relative toxicity of classes of antidepressants and individual antidepressants. The first approach was to relate drug-specific poisoning mortality rates to prescription rates termed the 'fatal toxicity index'. used approach, is to compare the rate of death with the rate of non-fatal self-poisoning, ${ }^{7,9}$ which generates a 'case fatality' index. The fatal toxicity index approach is probably less accurate because it is more heavily influenced by prescribing policies, including use of some antidepressants for conditions other than depression, ${ }^{10}$ and selective prescribing, for example, based on the clinician's assessment of suicide risk i.e. 'confounding by indication'. The specific aims of the study were to provide up-to-date information on the relative toxicity of individual antidepressants that may assist clinicians in making decisions about prescribing and inform interventions by regulatory authorities.

\section{Method}

The antidepressants investigated in this study were the TCAs amitriptyline, clomipramine, dosulepin (dothiepin), doxepin, imipramine, nortriptyline, trimipramine, the serotonin and noradrenaline reuptake inhibitor (SNRI) venlafaxine, the noradrenergic and specific serotonergic antidepressant (NaSSA) mirtazapine, and the SSRIs citalopram, fluoxetine, fluvoxamine, paroxetine and sertraline. The period covered by the study was 2000-2006. Escitalopram was not included as it first became available in the UK in 2003.

\section{Prescriptions}

Data on antidepressant prescriptions dispensed in the community in the form of quarterly estimates for years 2000 to 2006 for the UK were obtained from the Medical Data Index and supplied by IMS Health Inc (www.imshealth.com). Data were for people of all ages. Mid-year population estimates for the UK for 20002006 were obtained from the Office for National Statistics. ${ }^{11}$ Rates of prescribing were calculated per 100000 population, for people of all ages, for the years 2000-2006 combined.

\section{Deaths}

Information on drug-poisoning deaths receiving a verdict of suicide or death of undetermined intent that involved the antidepressants under investigation was provided by the Office for National Statistics, based on death registrations during 
2000-2006 in England and Wales. In England and Wales it has been customary to assume that the majority of injuries and poisonings of undetermined intent are cases where the harm was self-inflicted but there was insufficient evidence to prove that the deceased intended to kill themselves. ${ }^{12,13}$ We have restricted our analyses to deaths involving single drugs or single drugs and alcohol. Data were obtained for males and females separately for all drugs. Mortality rates were calculated as the number of deaths per 100000 population in England and Wales, for people aged 10 years and over.

\section{Self-poisoning}

Self-poisoning data came from three centres currently involved in the Multicentre Monitoring of Self-harm project (see Hawton et $a l^{2}$ for a description of the first phase of this project). Data were collected on all people who presented with self-harm to emergency departments at general hospitals in Oxford (one hospital), Manchester (three hospitals) and Derby (two hospitals) during the study period. Self-harm is defined as intentional self-poisoning or self-injury, irrespective of motivation. ${ }^{14}$ Selfpoisoning includes the intentional ingestion of more than the prescribed amount of any drug, or other non-ingestible substance, whether or not there is evidence that the act was intended to result in death. Data were collected on gender, age, date of self-harm and method of self-harm, including which $\operatorname{drug}(\mathrm{s})$ were ingested in overdoses. The analyses for non-fatal self-poisoning were based on all non-fatal overdoses of the antidepressants, including those with other drugs (with or without alcohol).

Episodes of self-poisoning involving the antidepressants for people aged 10 years and over for the defined population areas of Oxford City (mean annual population 128411), Manchester City (381 236) and Derby Unitary Area (204032) were included in the study. Mid-year population estimates for these areas for 2000-2006 were obtained from the Office for National Statistics. ${ }^{11}$ Rates of self-poisoning per 100000 population were calculated for these areas combined.

\section{Statistical analysis}

\section{Fatal toxicity index}

Rate ratios for drug-specific poisoning mortality relative to prescribing rates were calculated from the mortality rate (numerator) and the prescription rate (denominator).

\section{Case fatality}

Rate ratios for poisoning mortality relative to non-fatal selfpoisonings for specific drugs were calculated from the mortality rate (numerator) and the self-poisoning rate (denominator).

Relative toxicity indices were calculated by standardising the rate ratios to amitriptyline. This drug is used as the reference preparation in many studies.

Rate ratios and 95\% confidence intervals, Spearman's rho and heterogeneity were calculated using Stata version 10.0 for Windows.

\section{Ethical approval}

Oxford and Derby both have approval from local health/ psychiatric research ethics committees to collect data on self-harm for local monitoring and multicentre projects. Self-harm monitoring in Manchester is part of a clinical audit system, and has been ratified by the local research ethics committees. All monitoring systems are fully compliant with the provisions of the Data Protection Act of 1998. All centres also have approval under Section 251 of the National Health Service Act 2006 (formerly section 60 of the Health and Social Care Act 2001) regarding the use of patient identifiable information.

\section{Results}

The total numbers of deaths, prescriptions and episodes of selfpoisoning are given in Table 1 (see online Table DS1 for data stratified by gender). The antidepressants most frequently involved in suicide deaths were (in order) dosulepin, amitriptyline, venlafaxine and citalopram. For non-fatal poisonings the most frequently involved antidepressants were (in order) fluoxetine, citalopram, amitriptyline, paroxetine, venlafaxine, dosulepin, sertraline and mirtazapine (Table 1). These patterns were similar in both genders.

\section{Fatal toxicity index (mortality to prescriptions ratio)}

There was significant heterogeneity in fatal toxicity within the TCA group $\left(\chi^{2}=365.02\right.$, d.f. $\left.=6, P<0.001\right)$. The mortality to prescriptions rate ratio was considerably higher for dosulepin and doxepin than for amitriptyline (Table 2). This is reflected in the toxicity ratios relative to amitriptyline for these drugs (dosulepin 3.2, doxepin 2.5). The fatal toxicity ratios were generally far higher in males than females but the relative toxicity indices were mostly similar in males and females.

The relative toxicity index for venlafaxine (0.46) was approximately half that for amitriptyline but over five times higher than that for the SSRIs (0.08). The relative toxicity index for mirtazapine (0.32) was slightly lower than that of venlafaxine.

There was significant heterogeneity in fatal toxicity within the SSRI group $\left(\chi^{2}=28.76\right.$, d.f. $\left.=4, P<0.001\right)$. The fatal toxicity index for citalopram was three times higher than that for the other SSRIs (1.7, 95\% CI $1.3-2.3$ v. $0.6,95 \%$ CI $0.4-0.8)$, with a threefold higher relative toxicity index $(0.15 v .0 .05)$.

\section{Case fatality (mortality to self-poisonings ratio)}

There was significant heterogeneity in the relative toxicity within the TCA group $\left(\chi^{2}=123.01\right.$, d.f. $\left.=6, P<0.001\right)$. The mortality to self-poisonings rate ratio was significantly higher for dosulepin and doxepin than amitriptyline (Table 3 ). The relative toxicity indices for both dosulepin and doxepin suggest that these are two to three times more toxic than amitriptyline. There was a particularly high relative toxicity index for doxepin in females and for trimipramine in males (although the $95 \%$ CIs for the rate ratios were wide).

The relative toxicity index for venlafaxine $(0.29)$ was much lower than for the TCAs (1.6). However, it was considerably greater than for the SSRIs (0.06). The relative toxicity index for mirtazapine (0.22) was slightly lower than that of venlafaxine, although no different in females.

There was significant heterogeneity in relative toxicity in the SSRI drug group $\left(\chi^{2}=33.88\right.$, d.f. $\left.=4, P<0.001\right)$. Citalopram had a higher case fatality than the other four SSRIs $(1.1,95 \% \mathrm{CI}$ $0.8-1.4$ v. $0.3,95 \%$ CI $0.2-0.4)$, which was reflected in a threefold greater relative toxicity index $(0.12 v .0 .04)$.

\section{Comparison of fatal toxicity and case fatality}

There was a very high correlation between the rankings of the results of the fatal toxicity and case fatality approaches to estimating relative toxicity of the specific antidepressants (Spearman's rho $=0.99, P<0.001)$. 


\begin{tabular}{|c|c|c|c|c|c|c|}
\hline & $\begin{array}{l}\text { Deaths in England } \\
\text { and Wales, } n\end{array}$ & $\begin{array}{c}\text { Death rate per } \\
100000\end{array}$ & $\begin{array}{l}\text { Prescriptions } \\
\text { in UK, } n^{\mathrm{b}}\end{array}$ & $\begin{array}{l}\text { Prescription rate } \\
\text { per } 100000\end{array}$ & $\begin{array}{l}\text { Self-poisonings in } \\
\text { three centres, } n\end{array}$ & $\begin{array}{c}\text { Self-poisoning } \\
\text { rate per } 100000\end{array}$ \\
\hline \multicolumn{7}{|l|}{ TCAS } \\
\hline Amitriptyline & 395 & 0.1211 & 44286108 & 10606 & 704 & 14.09 \\
\hline Clomipramine & 39 & 0.0120 & 3544517 & 849 & 48 & 0.96 \\
\hline Dosulepin & 589 & 0.1807 & 20812372 & 4984 & 388 & 7.77 \\
\hline Doxepin & 22 & 0.0067 & 1001373 & 240 & 15 & 0.30 \\
\hline Imipramine & 25 & 0.0077 & 2575206 & 617 & 30 & 0.60 \\
\hline Nortriptyline & 5 & 0.0015 & 645175 & 155 & 7 & 0.14 \\
\hline Trimipramine & 13 & 0.0040 & 1113166 & 267 & 14 & 0.28 \\
\hline All seven TCAs & 1088 & 0.3338 & 73977917 & 17717 & 1206 & 24.14 \\
\hline SNRI: venlafaxine & 83 & 0.0255 & 20100751 & 4814 & 508 & 10.17 \\
\hline NaSSA: mirtazapine & 18 & 0.0055 & 6386479 & 1529 & 149 & 2.98 \\
\hline \multicolumn{7}{|l|}{ SSRIS } \\
\hline Citalopram & 50 & 0.0154 & 37371364 & 8950 & 719 & 14.39 \\
\hline Fluoxetine & 17 & 0.0052 & 39818056 & 9536 & 885 & 17.71 \\
\hline Fluvoxamine & 0 & 0 & 195897 & 47 & 13 & 0.26 \\
\hline Paroxetine & 10 & 0.0031 & 25980311 & 6222 & 556 & 11.13 \\
\hline Sertraline & 8 & 0.0025 & 15374325 & 3682 & 315 & 6.31 \\
\hline All five SSRIS & 85 & 0.0261 & 118739953 & 28437 & 2488 & 49.80 \\
\hline
\end{tabular}

\begin{tabular}{|c|c|c|c|c|c|c|}
\hline & \multicolumn{2}{|c|}{ Both genders } & \multicolumn{2}{|c|}{ Males } & \multicolumn{2}{|c|}{ Females } \\
\hline & $\begin{array}{c}\text { Rate ratio } \\
(95 \% \mathrm{Cl})\end{array}$ & $\begin{array}{c}\text { Relative } \\
\text { toxicity index }\end{array}$ & $\begin{array}{l}\text { Rate ratio } \\
(95 \% \mathrm{Cl})\end{array}$ & $\begin{array}{c}\text { Relative } \\
\text { toxicity index }\end{array}$ & $\begin{array}{c}\text { Rate ratio } \\
(95 \% \mathrm{Cl})\end{array}$ & $\begin{array}{c}\text { Relative } \\
\text { toxicity index }\end{array}$ \\
\hline \multicolumn{7}{|l|}{ TCAS } \\
\hline Amitriptyline & $11.4(10.3-12.6)$ & 1.0 & $20.3(17.7-23.2)$ & 1.0 & $7.5(6.5-8.7)$ & 1.0 \\
\hline Clomipramine & $14.1(10.0-19.3)$ & 1.2 & $15.9(8.4-27.1)$ & 0.8 & $13.3(8.7-19.5)$ & 1.8 \\
\hline Dosulepin & $36.3(33.4-39.3)$ & 3.2 & $70.5(62.9-78.8)$ & 3.5 & $23.3(20.6-26.2)$ & 3.1 \\
\hline Doxepin & $28.1(17.6-42.6)$ & 2.5 & $60.1(32.0-102.7)$ & 3.0 & $15.9(7.3-20.1)$ & 2.1 \\
\hline Imipramine & $12.4(8.1-18.4)$ & 1.1 & $17.0(8.5-30.4)$ & 0.8 & $10.2(5.6-17.2)$ & 1.4 \\
\hline Nortriptyline & $9.9(3.2-23.2)$ & 0.9 & 0 & - & $13.3(4.3-31.0)$ & 1.8 \\
\hline Trimipramine & $15.0(8.0-25.6)$ & 1.3 & $35.1(15.2-69.2)$ & 1.7 & $7.8(2.5-18.1)$ & 1.0 \\
\hline All seven TCAs & $18.8(17.7-20.0)$ & 1.7 & $33.7(31.0-36.5)$ & 1.7 & $12.6(11.6-13.8)$ & 1.7 \\
\hline SNRI: venlafaxine & $5.3(4.2-6.6)$ & 0.46 & $8.7(6.4-1.6)$ & 0.43 & $3.5(2.5-4.9)$ & 0.47 \\
\hline NaSSA: mirtazapine & $3.6(2.1-5.7)$ & 0.32 & $4.1(1.8-8.1)$ & 0.20 & $3.3(1.6-6.0)$ & 0.44 \\
\hline \multicolumn{7}{|l|}{ SSRIS } \\
\hline Citalopram & $1.7(1.3-2.3)$ & 0.15 & $3.3(2.2-4.7)$ & 0.16 & $1.0(0.6-1.6)$ & 0.14 \\
\hline Fluoxetine & $0.5(0.3-0.9)$ & 0.05 & $0.6(0.2-1.3)$ & 0.03 & $0.5(0.3-1.0)$ & 0.07 \\
\hline Fluvoxamine & 0 & 0 & 0 & 0 & 0 & 0 \\
\hline Paroxetine & $0.5(0.2-0.9)$ & 0.04 & $1.1(0.4-2.2)$ & 0.05 & $0.2(0.05-0.6)$ & 0.03 \\
\hline Sertraline & $0.7(0.3-1.3)$ & 0.06 & $1.1(0.3-2.7)$ & 0.05 & $0.5(0.1-1.2)$ & 0.06 \\
\hline All five SSRIS & $0.9(0.7-1.1)$ & 0.08 & $1.6(1.2-2.1)$ & 0.08 & $0.6(0.4-0.8)$ & 0.08 \\
\hline
\end{tabular}

\section{Discussion}

We have used two methods for assessing relative toxicity of antidepressants, the fatal toxicity index and the case fatality index. Both are subject to limitations. However, the case fatality index is probably a more accurate indicator of relative toxicity, being less influenced by selective prescribing. The findings based on both approaches show that dosulepin and doxepin are considerably more toxic than amitriptyline. Because of extensive prescribing of dosulepin relative to doxepin (Table 1), attention regarding toxicity has mainly focused on the former drug. In the UK in December 2007 the Medicines and Healthcare products Regulatory Agency issued advice regarding dosulepin and measures to reduce the risk of fatal overdose. Since November 2007 pack sizes have been limited and packaging made safer. ${ }^{15}$ Our findings support the need for such measures but also highlight the need to extend these to doxepin.

There were some gender differences, especially in relation to doxepin where relative toxicity based on case fatality was greater in females than males, and trimipramine where relative toxicity was greater in males. These differences may be the result of chance 


\begin{tabular}{|c|c|c|c|c|c|c|}
\hline & \multicolumn{2}{|c|}{ Both genders } & \multicolumn{2}{|c|}{ Males } & \multicolumn{2}{|c|}{ Females } \\
\hline & $\begin{array}{c}\text { Rate ratio } \\
(95 \% \mathrm{Cl})\end{array}$ & $\begin{array}{c}\text { Relative } \\
\text { toxicity index }\end{array}$ & $\begin{array}{c}\text { Rate ratio } \\
(95 \% \mathrm{Cl})\end{array}$ & $\begin{array}{c}\text { Relative } \\
\text { toxicity index }\end{array}$ & $\begin{array}{c}\text { Rate ratio } \\
(95 \% \mathrm{Cl})\end{array}$ & $\begin{array}{c}\text { Relative } \\
\text { toxicity index }\end{array}$ \\
\hline \multicolumn{7}{|l|}{ TCAS } \\
\hline Amitriptyline & $8.6(7.8-9.5)$ & 1.0 & $11.0(9.5-12.5)$ & 1.0 & $6.9(5.9-8.0)$ & 1.0 \\
\hline Clomipramine & $12.5(8.9-17.0)$ & 1.4 & $20.3(10.8-34.7)$ & 1.9 & $10.3(6.7-15.1)$ & 1.5 \\
\hline Dosulepin & $23.3(21.4-25.2)$ & 2.7 & $29.6(26.4-33.1)$ & 2.7 & $18.6(16.5-21.0)$ & 2.7 \\
\hline Doxepin & $22.5(14.1-34.0)$ & 2.6 & $18.5(9.8-31.6)$ & 1.7 & 33.9 (15.5-64.3) & 4.9 \\
\hline Imipramine & $12.8(8.3-18.9)$ & 1.5 & $19.1(9.5-34.2)$ & 1.7 & $10.0(5.5-16.8)$ & 1.5 \\
\hline Nortriptyline & $11.0(3.6-25.5)$ & 1.3 & 0 & - & $18.8(6.1-43.9)$ & 2.7 \\
\hline Trimipramine & $14.2(7.8-24.3)$ & 1.7 & $62.5(27.0-123.1)$ & 5.7 & $6.3(2.0-14.6)$ & 0.9 \\
\hline All seven TCAs & $13.8(13.0-14.7)$ & 1.6 & $17.7(16.3-19.2)$ & 1.6 & $11.1(10.2-12.1)$ & 1.6 \\
\hline SNRI: venlafaxine & $2.5(2.0-3.1)$ & 0.29 & $4.0(2.9-5.3)$ & 0.36 & $1.7(1.2-2.3)$ & 0.25 \\
\hline NaSSA: mirtazapine & $1.9(1.1-2.9)$ & 0.22 & $2.4(1.0-4.7)$ & 0.20 & $1.6(0.7-2.9)$ & 0.23 \\
\hline \multicolumn{7}{|l|}{ SSRIS } \\
\hline Citalopram & $1.1(0.8-1.4)$ & 0.12 & $1.8(1.2-2.5)$ & 0.12 & $0.7(0.4-1.1)$ & 0.10 \\
\hline Fluoxetine & $0.3(0.2-0.5)$ & 0.03 & $0.3(0.1-0.6)$ & 0.02 & $0.3(0.2-0.5)$ & 0.04 \\
\hline Fluvoxamine & 0 & 0 & 0 & 0 & 0 & 0 \\
\hline Paroxetine & $0.3(0.1-0.5)$ & 0.03 & $0.5(0.2-1.0)$ & 0.05 & $0.1(0.03-0.4)$ & 0.02 \\
\hline Sertraline & $0.4(0.2-0.8)$ & 0.05 & $0.6(0.2-1.5)$ & 0.05 & $0.3(0.08-0.7)$ & 0.04 \\
\hline All five SSRIs & $0.5(0.4-0.7)$ & 0.06 & $0.8(0.6-1.1)$ & 0.07 & $0.4(0.3-0.5)$ & 0.05 \\
\hline
\end{tabular}

because of low numbers. They could also reflect differences in prescribing patterns (e.g. dosages) for the two genders.

Venlafaxine is clearly far less toxic in overdose than the TCAs. Its relative toxicity index based on both assessment approaches was intermediate between TCAs and SSRIs. In the UK the Medicines and Healthcare products Regulatory Agency issued a warning about the relatively high toxicity of venlafaxine in 2006, recognising that selective prescribing to individuals at risk of suicide could be a contributory factor to this finding. ${ }^{16}$ The regulatory body also issued prescribing advice, including restricting pack sizes and initial supplies for patients. ${ }^{16}$ In our study the relative toxicity of mirtazapine was slightly lower than that of venlafaxine, but considerably greater than for the SSRIs.

Within the SSRIs, citalopram had a higher relative toxicity index, both based on the fatal toxicity measure and that using case fatality. This finding is in keeping with other reported concerns about toxicity of citalopram ${ }^{17,18}$ and may reflect known cardiotoxic $^{17}$ and proconvulsant ${ }^{7}$ effects of citalopram in overdose. Although the absolute fatal toxicity is low, this finding should nevertheless be considered when making risk-benefit decisions regarding prescribing for individual patients.

\section{Limitations and strengths of the study}

One limitation is that data for different factors were derived from different areas: prescribing for the UK, deaths for England and Wales, and non-fatal poisonings for three local centres. We have made the assumption that they are all reasonably representative of the UK. This may be a particular limitation for the data on non-fatal self-poisonings, especially as the catchment areas used in this study are cities. We have commented elsewhere about differences in self-poisoning rates relative to prescribing patterns in the three centres. ${ }^{19}$ These were limited and unlikely to substantially bias our overall findings. The populations of all three centres include people from a wide range of socioeconomic backgrounds.

For fatal self-poisoning we have focused on single antidepressant overdoses (with or without alcohol), in order to avoid cross-contamination of the results with other drugs. However, certain antidepressants may be more toxic in overdose when combined with other drugs (e.g. doxepin and amitriptyline). ${ }^{20}$ Also, we have not been able to take account of the size of overdoses, which may be influenced by local prescribing practices and use of antidepressants for indications other than depression (especially when lower doses may be used). For nonfatal self-poisonings we included both episodes of single drugs and those involving other drugs. The non-fatal self-poisonings are based on episodes that resulted in presentation to hospital. There are likely to be other cases where self-poisoning does not result in hospital presentation, ${ }^{21}$ so that the case fatality rates may be overestimated. The prescription data we used were only available for all ages.

One factor that could influence the findings is differential use of specific antidepressants in overdoses, which is likely to reflect differences in indications used when they are prescribed. Elsewhere we have confirmed that this is the case for venlafaxine; which tends to be more often prescribed for, and taken in overdose by, people with longer-term psychiatric disorders and a history of self-harm. ${ }^{19}$

The international applicability of the findings may be limited because of differences in regulatory advice, availability of specific antidepressants and prescribing practices between countries. Therefore country-specific and international comparative studies are warranted.

A major strength of the study is that we have used two approaches to assessing relative toxicity, the findings of which are remarkably similar. The data on non-fatal self-poisoning have come from three well-established monitoring systems. Also, by using 7 years of data the study has considerable statistical power.

\section{Implications}

Of the TCAs, dosulepin and doxepin have the greatest toxicity based on overdose deaths both relative to prescriptions and relative to non-fatal self-poisonings. Venlafaxine appears to be far less toxic that the TCAs but more toxic than the SSRIs and 
slightly more toxic than mirtazapine. Of the five SSRIs that we examined, citalopram appears to be more toxic than the other four. When prescribing antidepressants the clinician should take account of the risk that may be associated with an overdose, especially in someone judged to be at risk of self-poisoning, as well as relative efficacy, acceptability and possible interactions with other medication and alcohol, and concurrent physical morbidity. We suggest that the assessment of the relative toxicity of antidepressants should continue as new antidepressants are marketed and that international comparisons are warranted in view of differences between countries in prescribing practices.

\section{Funding}

This work was funded by a National Institute of Health Research (NIHR) Programme Gran for Applied Research (RP-PG-0606-1247) and K.H. and D.G. are NIHR Senior Investigators. The data on non-fatal self-poisoning were from a Department of Health funded multicentre study on self-harm. The views and opinions expressed in this paper do not necessarily reflect those of the Department of Health/NIHR or NHS. K.H. is also supported by Oxfordshire and Buckinghamshire Mental Health NHS Foundation Trust.

\section{Acknowledgement}

We thank Professor Philip Cowen for his advice and comments on the manuscript.

Keith Hawton, DSC, Helen Bergen, PhD, Sue Simkin, BA, Centre for Suicide Research, University of Oxford, Department of Psychiatry, Warneford Hospital, Oxford Jayne Cooper, PhD, Centre for Suicide Prevention, University of Manchester, Manchester; Keith Waters, RMN, Derbyshire Mental Health Service NHS Trust, Mental Health Resource Centre, Rehabilitation Centre, Royal Derby Hospital, Derby; David Gunnell, PhD, Department of Social Medicine, University of Bristol, Bristol; Navneet Kapur, MD, Centre for Suicide Prevention, University of Manchester, Manchester, UK

Correspondence: Keith Hawton, Centre for Suicide Research, University of Oxford, Department of Psychiatry, Warneford Hospital, Headington, Oxford OX3 7JX, UK. Email: keith.hawton@psych.ox.ac.uk

First received 30 Jun 2009, final revision 21 Nov 2009, accepted 28 Jan 2010

\section{References}

1 Office for National Statistics. Deaths related to drug poisoning in England and Wales, 2002-06. Health Stat $Q$ 2007; 36: 66-72.

2 Hawton K, Bergen H, Casey D, Simkin S, Palmer B, Cooper J, et al. Self-harm in England: a tale of three cities. Multicentre study of self-harm. Soc Psychiatry Psychiatr Epidemiol 2007; 42: 513-21.

3 Cavanagh JTO, Carson AJ, Sharpe M, Lawrie SM. Psychological autopsy studies of suicide: a systematic review. Psychol Med 2003; 33: 395-405.
4 Hawton $\mathrm{K}$ (ed). Restriction of access to methods of suicide as a means of suicide prevention. In Prevention and Treatment of Suicidal Behaviour: From Science to Practice: 279-91. Oxford University Press, 2005.

5 Tournier M, Grolleau A, Cougnard A, Molimard M, Verdoux H. Factors associated with choice of psychotropic drugs used for intentional drug overdose. Eur Arch Psychiatry Clin Neurosci 2009; 259: 86-91.

6 Buckley NA, McManus PR. Fatal toxicity of serotonergic and other antidepressant drugs: analysis of United Kingdom mortality data. BMJ 2002; 325: $1332-3$

7 White N, Litovitz T, Clancy C. Suicidal antidepressant overdoses: a comparative analysis by antidepressant type. J Med Toxicol 2008; 4: 238-50.

8 Henry JA. A fatal toxicity index for antidepressant poisoning. Acta Psychiatr Scand Suppl 1989; 80: 37-45.

9 Rose JC, Unis AS. A mortality index for postmarketing surveillance of new medications. Am J Emerg Med 2000; 18: 176-9.

10 Lawrenson RA, Tyrer F, Newson RB, Farmer RDT. The treatment of depression in UK general practice: selective serotonin reuptake inhibitors and tricyclic antidepressants compared. J Affect Disord 2000; 59: 157.

11 Office for National Statistics. Population estimates for UK, England and Wales, Scotland and Northern Ireland - current datasets. ONS, 2008 (http://www.statistics.gov.uk/statbase/Product.asp?vInk=15106).

12 Adelstein A, Mardon C. Suicides 1961-74. Popul Trends 1975; 2: 13-8.

13 Brock A, Baker A, Griffiths C, Jackson G, Fegan G, Marshall D. Suicide trends and geographical variations in the United Kingdom, 1991-2004. Health Stat $Q$ 2006; 31: 6-22.

14 Hawton K, Harriss L, Hall S, Simkin S, Bale E, Bond A. Deliberate self-harm in Oxford, 1990-2000: a time of change in patient characteristics. Psychol Med 2003; 33: 987-96.

15 Medicines and Healthcare products Regulatory Agency. Dosulepin: measures to reduce risk of fatal overdose. Drug Safety Update 2007; 1: 7-8.

16 Medicines and Healthcare products Regulatory Agency. Venlafaxine (Efexor). Summary of Basis for Regulatory Position. MHRA, 2006 (http:// www.mhra.gov.uk/Safetyinformation/Safetywarningsalertsandrecalls/ Safetywarningsandmessagesformedicines/CON2023846).

17 Kelly CA, Dhaun N, Laing WJ, Strachan FE, Good AM, Bateman DN. Comparative toxicity of citalopram and the newer antidepressants after overdose. Clin Toxicol 2005; 42: 67-71.

18 Flanagan RJ. Fatal toxicity of drugs used in psychiatry. Hum Psychopharmacol 2008; 23: 43-51.

19 Bergen H, Murphy E, Cooper J, Kapur N, Stalker C, Waters K, et al. A comparative study of non-fatal self-poisoning with antidepressants relative to prescribing in three centres in England. J Affect Disord 2009; Oct 26 (Epub ahead of print).

20 Koski A, Ojanperä I, Vuori E. Interaction of alcohol and drugs in fatal poisonings. Hum Exp Toxicol 2003; 22: 281-7.

21 Hawton K, Rodham K, Evans E, Weatherall R. Deliberate self-harm in adolescents: self report survey in schools in England. BMJ 2002; 325: 1207-11. 